\title{
Analytical Case Study on a Dedicated Pigment in Recycling Processes of Polyethylene
}

\section{Kees Miermans*, Ellen Dijkman, Petra Krystek}

The Netherlands Organization for Applied Scientific Research (TNO), Unit Circular Economy and Environment-Environmental Modelling, Sensing \& Analysis (CEE-EMSA), Utrecht, The Netherlands

Email: ^kees.miermans@tno.nl

How to cite this paper: Miermans, K., Dijkman, E. and Krystek, P. (2020) Analytical Case Study on a Dedicated Pigment in Recycling Processes of Polyethylene. Advances in Chemical Engineering and Science, 10, 181-189.

https://doi.org/10.4236/aces.2020.103013

Received: April 8, 2020

Accepted: June 16, 2020

Published: June 19, 2020

Copyright $\odot 2020$ by author(s) and Scientific Research Publishing Inc. This work is licensed under the Creative Commons Attribution International License (CC BY 4.0).

http://creativecommons.org/licenses/by/4.0/

\begin{abstract}
The ability to track \& trace materials is a key feature in the entire chain, and it ensures circularity principles. Examples from plastic recycling show the enormous added value that analytical technology can have for the circular economy. During polymer production and recycling processes, pigments can be added for different purposes; e.g. as colouring agent of the polymeric product but also as tracer for tracking process development and control in the final recycle products versus possible by-products. An analytical method for tracking the pigment Solvent Blue 15 in input materials, in intermediates as well as in recyclates was developed by tracing and quantifying an indicator metal which is copper $(\mathrm{Cu})$. Therefore, suitable digestion procedures and a quantification method by high resolution inductively coupled plasma mass spectrometry (HR-ICP-MS) were developed and used for measuring the polymeric digests. The method was tested on relevant samples from chemical recycling processes. The background concentrations in base/raw material are in the range of $0.05-0.1 \mathrm{mg} \cdot \mathrm{kg}^{-1} \mathrm{Cu}$. The processing concentrations are in the range of 4.2 to $28 \mathrm{mg} \cdot \mathrm{kg}^{-1} \mathrm{Cu}$, while the pigment starting material (polyethylene, $\mathrm{PE}$ ) has a concentration of around $50 \mathrm{mg} \cdot \mathrm{kg}^{-1} \mathrm{Cu}$.
\end{abstract}

\section{Keywords}

Cupper, Pigment Solvent Blue, Recycled Polyethylene, Track \& Trace, High Resolution Inductively Coupled Plasma Mass Spectrometry (HR-ICPMS)

\section{Introduction}

The benefits of plastics, especially versatility, resistance and durability to degradation, are well known and led to the actual definition of "Age of Plastics", where almost everything contains this material. The production increased tre- 
mendously to more than 300 million tons worldwide. Plastic materials also pose a serious threat to the marine environment when not properly disposed or recycled [1]. A lot of pollution is introduced to the environment. To avoid pollutions, it is advisable to recycle plastics [2]. This is a need to implement adequate controls in the development of recycling processes and thereby control the process and guide. Also, plastics in toys can be harmful; especially for children while high concentrations of heavy metals above international limits were found in earlier studies [3]. Al-Qutob et al. have developed a method for analysing lead $(\mathrm{Pb})$, cadmium $(\mathrm{Cd})$, chromium $(\mathrm{Cr})$, mercury $(\mathrm{Hg})$, arsenic (As), selenium (Se), barium $(\mathrm{Ba})$, and zinc $(\mathrm{Zn})$ with Inductively Coupled Plasma Mass Spectrometry (ICP-MS), in toys [3]. The samples were crushed and dipped for 8 hours in a solution of artificial saliva. However, this is not a total digestion, but a risk related leaching approach.

Other analytical approaches are developed based on inductively coupled plasma isotope dilution mass spectrometric (ICP-IDMS) for selected metals $(\mathrm{Pb}$, $\mathrm{Cd}, \mathrm{Cr}$, and $\mathrm{Hg}$ ) and thermal ionization isotope dilution mass spectrometry (TI-IDMS) in polyolefins [4]. The ICP-IDMS method supposed to be a routine method while enriched isotopes as ${ }^{206} \mathrm{~Pb},{ }^{116} \mathrm{Cd},{ }^{53} \mathrm{Cr}$ and ${ }^{201} \mathrm{Hg}$ were used. Because of its high first ionization potential of mercury $(\mathrm{Hg})$ and its high volatility, $\mathrm{Hg}$ could not be determined by TI-IDMS. The TI-IDMS is not suitable for routine analysis. Digestion of the samples was carried out with concentrated nitric acid $\left(\mathrm{HNO}_{3}\right)$ at temperatures of about $300^{\circ} \mathrm{C}$ in a high pressure asher (HPA).

Sakurai et al. [5] developed sample digestion method for determination of Cd, $\mathrm{Cr}$ and $\mathrm{Pb}$ in polyethylene and polyvinylchloride (PVC) by using a microwave oven. The metals were determined with Inductively Coupled Plasma Atomic Emission Spectroscopy (ICP-AES). As reference material BCR-680 was used. In addition to the ICP-AES analysis, Energy Dispersive X-ray Spectroscopy (EDS) has been carried out. The samples were digested with nitric acid and a combination of nitric and sulfuric acid. Sulfuric gave lower recovery of lead because of precipitation of lead sulphate. This X-ray analysis was used for identifying other elements like carbon $(\mathrm{C})$, fluorine $(\mathrm{F})$, oxygen $(\mathrm{O})$, silicon $(\mathrm{Si})$ and titanium $(\mathrm{Ti})$. The digestion methods microwave-induced combustion (MIC) and microwave-assisted acid digestion (MW-AD) were evaluated for further As, bismuth (Bi), Cd, cobalt (Co), Cu, Hg, manganese (Mn), molybdenum (Mo), nickel (Ni), $\mathrm{Pb}$, antimony $(\mathrm{Sb})$, strontium $(\mathrm{Sr}), \mathrm{Ti}$, vanadium $(\mathrm{V})$ and $\mathrm{Zn}$ determination by ICP-MS and ICP-AES [6]. Several types of plastics such as low-density polyethylene (LDPE) and high density polyethylene (HDPE) were investigated. Accuracy for all the analytes determined by ICP-AES and ICPMS after MIC digestion was better than $95 \%$.

For overall knowledge of how polymers are analysed, an interlaboratory test on polymers was organized [7]. Three different heavy metals ( $\mathrm{Pb}, \mathrm{Cr}$ and $\mathrm{Cd}$ ) in polyvinylchloride and polyurethane were contaminated homogeneously with precise quantities of the three heavy metals. Twelve laboratories have partici- 
pated the interlaboratory test and analysed the metals with ICP-OES or AAS. Cd and $\mathrm{Pb}$ obtained coefficients of variations of $8.5 \%$ for $\mathrm{Cd}$ and of $8.9 \%$ for $\mathrm{Pb}$ for concentrations of around $100 \mathrm{mg} \cdot \mathrm{kg}^{-1}$. Chromium can form insoluble chromium carbide during digestion which leads in the end to lowered chromium recoveries.

Polyethylene can also be analysed with X-ray Fluorescence (XRF) Spectrometry [8] which is often used in the plastic industry. The method is useful for a fast analysis of e.g. $\mathrm{Cd}, \mathrm{Pb}, \mathrm{Hg}, \mathrm{Cr}, \mathrm{As}, \mathrm{Ni}, \mathrm{Cu}, \mathrm{Zn}$ and $\mathrm{Br}$ at the sub-ppm level.

Swagten et al. [9] developed a method for the calibration of polyethylene reference material with Neutron Activation Analysis ( $k_{0}$-NAA) and ICP-AES. The analytical results of the elements $\mathrm{Na}, \mathrm{Al}, \mathrm{Ca}, \mathrm{Ti}$ and $\mathrm{Zn}$ were in a concentration range from 5 up to $600 \mathrm{mg} \cdot \mathrm{kg}^{-1}$ obtained by $k_{0}$-NAA and ICP-AES; all results were in agreement within 1 standard deviation (SD). However, the $k_{0}$-NAA is often not suitable for routine analysis due to its high time consumption.

For the determination of $\mathrm{Cr}, \mathrm{Cd}$ and $\mathrm{Pb}$ in food-packaging materials, an axial inductively coupled plasma time-of-flight mass spectrometry (ICP-TOF-MS) [10], was used. The detection limits are in the range of 0.02 to $0.07 \mathrm{ng} \cdot \mathrm{g}^{-1}$ for the four metals. Recent publications on the analysis of metals in plastics focus on environmental issues like marine littering. Turner et al. [11] [12] investigated several elements (among which $\mathrm{Cu}$ ) in marine litter in the south of England by using a field-portable-XRF [11]. Prunier et al. [13] investigated four elements in polyethylene debris from the North Atlantic subtropical gyre with ICP-MS.

Our study focuses on samples from the process of technological developments for the recycling of polyethylene. At this moment, this process is still in development and therefore special and variable setups are tested which leads to also variable sample composition. For process control, a dedicated pigment (Solvent Blue) which contains $\mathrm{Cu}$ was added prior processing. By track \& trace of $\mathrm{Cu}$ in different fractions and stages of the recycling process, the process developers will receive crucial information about e.g. separation efficiency of fractions. However, as in most studies the complete polymer digestion is nearly always the bottleneck of method development.

In first instance, open digestion with disposable vessels was examined due to its time efficiency. Different compositions of digestion media and digestion circumstances were tested while a maximum temperature of $110^{\circ} \mathrm{C}$ was used. But the polyethylene granulates were not sufficiently digested.

Applying open digestion is therefore incomplete and a not workable method. Therefore, preferably closed digestion with a microwave was chosen. Several mixtures of acids were tested. For example, sulfuric or hydrochloric acid, but for high resolution inductively coupled plasma mass spectrometry (HR-ICP-MS) analyse these acids are less suitable due to a lot of interferences. Based on this pre-work, we developed an analytical method for the trace determination of cupper in polyethylene samples and we applied this method successfully for input, intermediate and output samples of the polyethylene recycling. 


\section{Experimental}

\subsection{Instrumentation}

For the open digestion a DigiPREP digestion system with 48 positions digestion block and Controller (SCP SCIENCE, Canada) was used. The $50 \mathrm{~mL}$ vessels are made of virgin polypropylene (SCP SCIENCE, Canada).

For the closed digestion of PE samples was performed using a commercial high-pressure laboratory microwave oven (CEM Corporation Matthews, NC, USA) operating at a frequency of $2450 \mathrm{~Hz}$ with an energy output of $1600 \mathrm{~W}$. This microwave digestion system is equipped with fourteen HP 500 Plus $100 \mathrm{~mL}$ perfluoro alkoxy vessels (CEM). The maximum operating temperature and pressure are $210^{\circ} \mathrm{C}$ and 24 bar, respectively.

All ICPMS-related measurements were performed with the Sector Field (SF) instrument; the HR-ICPMS ELEMENT XR (Thermo Scientific, Bremen, Germany). This instrument has three resolution modes; $R=300,4000$ and 10,000. Besides the normal counting/analog detector this instrument is equipped with a Faraday cup detector.

The ESI FAST SC-4 (Elemental Scientific, Omaha Nebraska, USA) loop injection autosampler was used for automation of the sampling. The details of this sample introduction system and the instrumental operating conditions are summarized in Table 1.

\subsection{Chemicals and Materials}

Concentrated nitric acid $\left(\mathrm{HNO}_{3}, 67 \% \mathrm{w} / \mathrm{w}\right)$ from the brand NORMATOM for trace metal analysis was supplied by VWR International, Amsterdam, The Netherlands.

For accurate quantitative determination an internal standard method is used, using Rhodium ( $\mathrm{Rh}=5 \mu \mathrm{g} \cdot \mathrm{L}^{-1}$; on-line addition; sample: IS; 2:1) as internal standard. The quantification of copper is done by external calibration (concentrations range: $0,5,10,20$ and $30 \mu \mathrm{g} \cdot \mathrm{L}^{-1} \mathrm{Cu}$ ). $\mathrm{ERM}^{\circledR}$-EC680m; Low Density Polyethylene (LDPE) is used as reference material (copper is not certified).

Milli-Q Advantage A10 water (Millipore, France) is used as pure water.

Several samples of polyethylene, characterized as follows, were measured:

A PE Reference batch (1); no dye;

B PE pigment starting material

C Cake Intermediate pigment MTBE*

D Cake Intermediate pigment treatment with $\mathrm{MTBE}^{*}, \mathrm{H}_{2} \mathrm{O}$ and $\mathrm{H}_{2} \mathrm{SO}_{4}$

E Base material LDPE 1965

F PE Reference batch (2); no dye

G ERM-EC680m Low-Density Polyethylene ( $\mathrm{Cu}$ not certified)

${ }^{\star}$ MTBE is methyl-tert-butyl ether which was used during the technical processing.

An overview of pictures of the samples is given in Figure 1. 

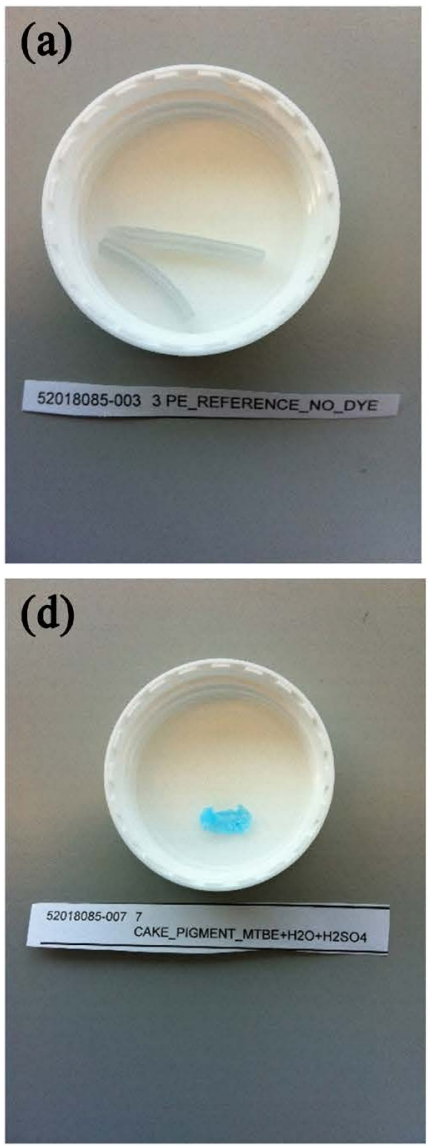

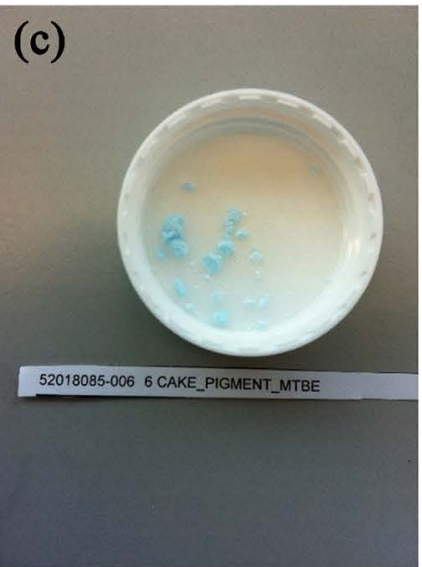

(f)

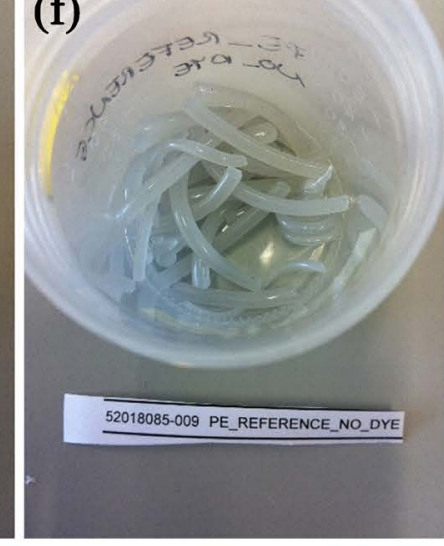

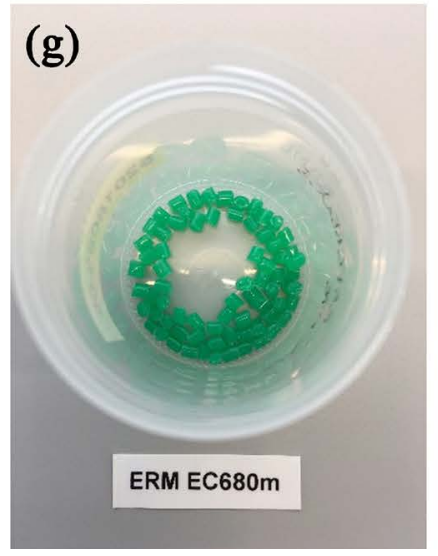

Figure 1. Samples and certified reference material. (a) PE reference (1); (b) PE pigment starting; (c) Intermediate pigment MTBE; (d) Pigment MTBE $+\mathrm{H}_{2} \mathrm{SO}_{4}$; (e) Base material LDPE; (f) PE reference (2); (g) ERM-EC $680 \mathrm{~m}$.

\subsection{Method}

About $130 \mathrm{mg}$ sample material was weighted into medicine cup and carried over in the microwave vessel. Afterwards $10 \mathrm{~mL}$ concentrated nitric acid were added and wait for two minutes. Afterwards, the microwave vessels were closed and the temperature program, which was used for decomposition of polyethylene samples was run; increase of temperature to $200^{\circ} \mathrm{C}$ and remaining at this temperature for 20 minutes). The maximum power was adjusted to 1600 Watt and 
Table 1. Instrument conditions used for the HR-ICPMS measurement.

\begin{tabular}{|c|c|}
\hline Parameter & Value \\
\hline Nebulizer & $100 \mathrm{~mL} / \mathrm{min}, \mathrm{PFA} \mathrm{ST}$ \\
\hline Spray chamber & Quartz cyclonic spray chamber \\
\hline Spray chamber cooler & $\mathrm{PC}^{3}$ Peltier Chiller $2^{\circ} \mathrm{C}$ \\
\hline Cones & Nickel "H" skimmer and Nickel sampler cone \\
\hline RF power & $1250 \mathrm{~W}$ \\
\hline Cool gas flow & $16 \mathrm{~L} \cdot \mathrm{min}^{-1} \mathrm{Ar}$ \\
\hline Auxiliary gas flow & $0.82 \mathrm{~L} \cdot \mathrm{min}^{-1} \mathrm{Ar}$ \\
\hline Sample gas flow & $1.055 \mathrm{~L} \cdot \mathrm{min}^{-1} \mathrm{Ar}$ \\
\hline \multirow[t]{2}{*}{ Isotopes } & ${ }^{63} \mathrm{Cu}$ (used for quantification) and ${ }^{65} \mathrm{Cu}$ \\
\hline & Internal standard ${ }^{103} \mathrm{Rh}$ \\
\hline Acquisition mode & E-scan \\
\hline Magnet mass & 62.929 for $\mathrm{Cu}$ and 102.924 for $\mathrm{Rh}$ \\
\hline Settling time & $0.300 \mathrm{~s}$ \\
\hline Acquisition/ "mass" window & $150 \%$ \\
\hline Search window & $50 \%$ \\
\hline Integration window & $60 \%$ \\
\hline Sample time & $0.01 \mathrm{~s}$ \\
\hline Samples per peak & 40 \\
\hline Detection mode & Counting \\
\hline Number of replicates & 9 \\
\hline
\end{tabular}

maximum pressure to 24 bar. After the digestion the samples are completed with Milli-Q water till about $20 \mathrm{~mL}$. The digests were analyses by HR-ICPMS. The related measuring parameters and the method are given in Table 1.

For quality control reason, Blanc destruction and ERM-EC680m were analysed.

\section{Results and Discussion}

Digestion is the bottleneck of method development. Different compositions of digestion media and digestion circumstances were tested.

In first instance, open digestion with disposable vessels was examined due to its time efficiency. After the open digestion, cleaning of the vessels is not necessary. Different compositions of digestion media and digestion circumstances were tested. In contrast to the closed microwave digestion, the highest temperature of the open digestion is $110^{\circ} \mathrm{C}$. Polyethylene granulates were not sufficiently digested. Applying open digestion is therefore incomplete and a not workable method. It has been decided to choose the closed digestion method.

For the $\mathrm{Cu}$ digestion, concentrated nitric acid is recommended. It is also possible to digest $\mathrm{Cu}$ with e.g. sulfuric or hydrochloric acid, but for HR-ICPMS analyses these acids are less suitable due to lots of interferences.

Before quantification $\mathrm{Cu}$ in the digested nitric acid samples, interference scans 
in the matrix of interest were carried in high resolution (HR) mode $(R=10,000)$. Examples of interference scans in HR mode are presented in Figure 2. In the PE matrix of Figure 2(a) the ${ }^{23} \mathrm{Na}^{40} \mathrm{Ar}$ is separated from ${ }^{63} \mathrm{Cu}$. The "chemical blank zoom" of the third mass spectrum the polyatomic ions of ${ }^{17} \mathrm{Al}^{38} \mathrm{Ar}$ and ${ }^{47} \mathrm{Ti}^{17} \mathrm{O}$ are also separated from ${ }^{65} \mathrm{Cu}$. The third mass spectrum is an enlargement of the second mass spectrum. Due to no significant interferences in HR mode, the MR mode $\mathrm{R}=4000$ was used.

In Table 2 the results of the quantitative analyses of $\mathrm{Cu}$ in polyethylene are presented. The samples are analysed in duplicate. The results of sample E (Base material LDPE) give a too high relative standard deviation. The detection limit of copper is $0.1 \mathrm{mg} \cdot \mathrm{kg}^{-1}$ and the mean concentration of sample $\mathrm{E}$ is $0.05 \mathrm{mg} \cdot \mathrm{kg}^{-1}$. The $\mathrm{Cu}$ concentration of sample $\mathrm{E}$ is below limit of detection of copper. This is the reason of the high spreading.

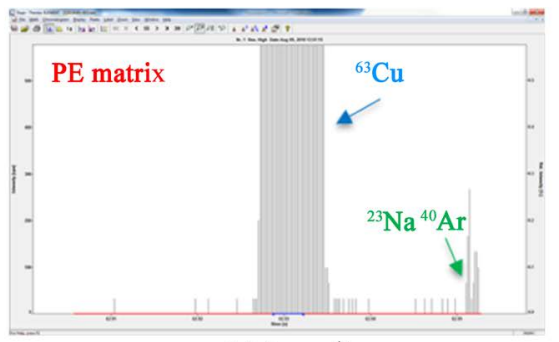

(a) $\left(\right.$ zoom $\left.^{*}\right)$

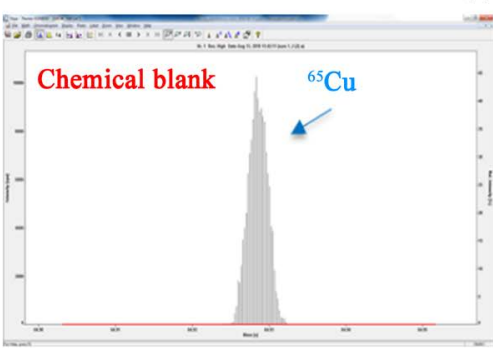

(b)

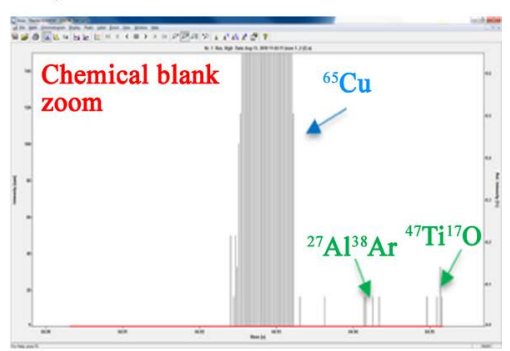

(c) (zoom*)

Remark: *only blue indicated signals from ${ }^{65} \mathrm{Cu}$ are integrated and evaluated; green indicated interferences are only shown for presenting possible next-by interferences within the closed mass range.

Figure 2. Interferences scans in high resolution mode $(\mathrm{R}=10,000)$.

Table 2. Results of $\mathrm{Cu}$ in PE processing samples.

\begin{tabular}{llcll}
\hline \multicolumn{1}{c}{ Sample description } & $\begin{array}{c}\mathrm{AVG}(\mathrm{n}=2) \\
{\left[\mathrm{mg} \mathrm{kg}^{-1} \mathrm{Cu}\right]}\end{array}$ & $\begin{array}{c}\text { RSD } \\
{[\%]}\end{array}$ & Remarks \\
\hline A PE reference, batch (1) & 4.6 & 14 & High deviation; processing background \\
B PE pigment starting material & 47 & 18 & High deviation \\
C Cake Intermediate pigment, treated with MTBE & 3.9 & 13 & High deviation \\
D Cake Intermediate pigment, treated with MTBE, $\mathrm{H}_{2} \mathrm{O}$ and $\mathrm{H}_{2} \mathrm{SO}_{4}$ & 13 & 9 & Low deviation \\
E Base material LDPE 1965 & 0.05 & $($ “125”) & Background Concentration/raw \\
F PE reference, batch (2) & 16 & $100 \quad$ Very high deviation also compared with A \\
G ERM-EC680m Low-density olyethylene & 12.5 & $10 \quad$ Processing background \\
$\quad$ Limit of Detection Cu & 0.1 & & Used as internal control sample (Cu not certified)
\end{tabular}


As reference material ERM-EC680m [5], made of LDPE, was analysed too. Unfortunately, $\mathrm{Cu}$ is not certified in this material, but this sample will be a suitable internal control material in quality control of upcoming series of samples.

An analytical method for tracing and quantifying copper $(\mathrm{Cu})$ from the pigment Solvent Blue $15(\mathrm{c}(\mathrm{Cu})$ 11\%) in PE has been developed and applied to six $\mathrm{PE}$ samples from a recycling process.

The background concentration in base/raw material is $0.05-0.1 \mathrm{mg} \cdot \mathrm{kg}^{-1} \mathrm{Cu}$. The processing background concentration is in the range of 4.2 to $28 \mathrm{mg} \cdot \mathrm{kg}^{-1}$ $\mathrm{Cu}$.

Methodological performance: Most samples show deviations of $10 \%$ to $15 \%$ in the duplicate results. This might be based on the inhomogeneous distribution of $\mathrm{Cu}$ in the samples; the use of lower sample amounts (as $130 \mathrm{mg}$ ) is not recommended. The use of higher sample amounts then $500 \mathrm{mg}$ is also not recommended.

\section{Conclusions}

Complete polyethylene digestion is the bottleneck of method development. Different compositions of digestion media and digestion circumstances were tested. A dedicated method for analysing copper in polyethylene is developed and tested with process technological samples of a blue pigment in recycled polyethylene. This approach shows high potential for the application of recycling processes of other types of plastics. The method of analysing metals in all kinds of plastics is very useful to track \& trace the metals in recycling processes.

Although a sample preparation method by microwave digestion is developed for the matrix polyethylene, the Teflon vessels (HP-500) are not stable enough and they break internally. Stronger vessel materials such as TFM (modified poly tetra fluorine ethane) are recommended and this material is much stronger than common vessel materials.

\section{Acknowledgements}

We thank our colleagues from TNO, department Sustainable Process \& Energy Systems (SPES) for supplying samples and an excellent project collaboration.

\section{Conflicts of Interest}

The authors declare no conflicts of interest regarding the publication of this paper.

\section{References}

[1] Avio, C.G., Gorbi, S. and Regoli, F. (2017) Plastics and Microplastics in the Oceans: From Emerging Pollutants to Emerged Threat. Marine Environmental Research, 128, 2-11. https://doi.org/10.1016/j.marenvres.2016.05.012

[2] EU Green Paper (2013) On a European Strategy on Plastic Waste in the Environment. Brussels, 7.3.2013 COM.

https://eur-lex.europa.eu/legal-content/EN/TXT/HTML/?uri=CELEX:52013DC012 
$\underline{3 \& \text { from }=\mathrm{EN}}$

[3] Al-Qutob, M., Asafra, A., Nashashibi, T. and Qutob, A.A. (2014) Determination of Different Trace Heavy Metals in Children's Plastic Toys Imported to the West Bank/Palestine by ICP/MS-Environmental and Health Aspect. Journal of Environmental Protection, 5, 1104-1110. https://doi.org/10.4236/jep.2014.512108

[4] Diemer, J. and Heumann, K.G. (2000) Development of an ICP-IDMS Method for Accurate Routine Analyses of Toxic Heavy Metals in Polyolefins and Comparison with Results by TI-IDMS. Fresenius Journal of Analytical Chemistry, 368, 103-110. https://doi.org/10.1007/s002160000469

[5] Sakurai, H., Noro, J., Kawasa, A., Fujinami, M. and Oguma, K. (2006) Digestion of Plastic Materials for Determination of Toxic Metals with a Microwave Oven for Household Use. Analytical Science, 22, 225-228.

https://www.jstage.jst.go.jp/article/analsci/22/2/22_2_225/_article/-char/ja/ https://doi.org/10.2116/analsci.22.225

[6] Pereira, J.S.F., Knorr, C.L., Pereira, L.S.F., Moraes, D.P., Paniz, J.N.G., Flores, E.M.M. and Knapp, G. (2011) Evaluation of Sample Preparation Methods for Polymer Digestion and Trace Elements Determination by ICPMS and ICPOES. Journal of Analytical Atomic Spectrometry, 26, 1849-1857.

https://pubs.rsc.org/en/content/articlelanding/2011/ja/clja10050e/unauth\#!divAbst $\underline{\text { ract }}$ https://doi.org/10.1039/c1ja10050e

[7] Ritter, A., Michel, E., Schmid, M. and Affolter, S. (2004) Interlaboratory Test on Polymers: Determination of Heavy Metals in Polymer Metrices. Polymer Testing, 23, 467-474. https://doi.org/10.1016/j.polymertesting.2003.09.001

[8] Swagten, J., Bossus, D. and Vanwersch, H. (2006) The Calibration of XRF Polyethylene Reference Materials with k0-NAA and ICP-AES. Nuclear Instruments and Methods in Physics Research A, 564, 761-765. https://doi.org/10.1016/j.nima.2006.04.001

[9] Wolksa, J. (2005) Safeguarding the Environment-XRF Analysis of Heavy Metals in Polyethylene. Plastics Additives and Compounding, 7, 36-39. https://doi.org/10.1016/s1464-391x(05)00334-x

[10] Skrzydlewska, E., Balcerzak, M. and Vanhaecke, F. (2003) Determination of Chromium, Cadmium and Lead in Food-Packaging Materials by Axial Inductively Coupled Plasma Time-of-Flight Mass Spectrometry. Analytica Chimica Acta, 479, 191-202. https://doi.org/10.1016/s0003-2670(02)01527-1

[11] Turner, A. and Solman, K.R. (2016) Analysis of the Elemental Composition of Marine Litter by Field-Portable-XRF. Talanta, 159, 262-271. https://doi.org/10.1016/j.talanta.2016.06.026

[12] Turner, A. (2016) Heavy Metals, Metalloids and Other Hazardous Elements in Marine Plastic Litter. Marine Pollution Bulletin, 111, 136-142. https://doi.org/10.1016/j.marpolbul.2016.07.020

[13] Prunier, J., Maurice, L., Perez, E., Gigault, J., Pierson Wickmann, A.-C., Davranche, M. and Ter Halle, A. (2018) Trace Metals in Polyethylene from the North Atlantic Subtropical Gyre. Environmental Pollution, 245, 371-379. https://doi.org/10.1016/j.envpol.2018.10.043 